\title{
LA SOJIZACIÓN EN ARGENTINA Y BRASIL (1980/2014): INFLUENCIA DE LAS POLÍTICAS PÚBLICAS, DE LAS EMPRESAS TRANSNACIONALES Y DE LA ESTRUCTURA ECONÓMICA DEPENDIENTE
}

\author{
José Pierri ${ }^{1}$ \\ Valdemar João Wesz Junior ${ }^{2}$
}

\section{RESUMEN}

Al largo de las últimas décadas, la soja se convirtió en la principal actividad agrícola en Brasil y Argentina. Este trabajo, partiendo de un enfoque histórico-político, procura evidenciar los principales condicionantes de la expansión de la soja en los dos países, enfatizando la influencia del factor externo (demanda y precio internacional), las diferentes políticas públicas y las grandes empresas transnacionales. Estos elementos procuran ir más allá de los argumentos que cifran en el espíritu empresario y el funcionamiento estricto de mecanismos de libre mercado como impulsores de la "sojización", que muchas veces predomina en los discursos de las entidades representativas de los productores primarios, agroindustria y de algunos investigadores vinculados al sector agrario. La investigación realiza una revisión bibliográfica del tema y analiza noticias publicadas en distintos periódicos y datos estadísticas oficiales de los dos países.

Palavras-chave: Argentina, Brasil, empresas transnacionales, políticas públicas, soja.

\section{A SOJIZAÇÃO NA ARGENTINA E NO BRASIL (1980/2014): INFLUÊNCIA DAS POLÍTICAS PÚBLICAS, DAS EMPRESAS TRANSNACIONAIS E DA ESTRUTURA ECONÔMICA DEPENDENTE}

\section{RESUMO}

Ao longo das últimas décadas, a soja tornou-se a principal atividade agrícola no Brasil e na Argentina. Este trabalho, partindo de um enfoque histórico-político, procura evidenciar os principais condicionantes da expansão da soja nos dois países, enfatizando a influencia dos fatores externos (demanda e preço internacional), das diferentes políticas públicas e das grandes empresas transnacionais. Esses elementos procuram ir além dos argumentos que trazem o espírito empresarial e o funcionamento estrito dos mecanismos de livre mercado como impulsor da sojização, que muitas vezes predomina no discurso das

\footnotetext{
${ }^{1}$ Profesor de la Facultad de Ciencias Económicas de la Universidad de Buenos Aires (FCE-UBA). E-mail: pierrijosea@gmail.com

Profesor de la Universidad Federal de la Integración Latinoamericana (UNILA). E-mail: jwesz@yahoo.com.br
} 
organizações representativas dos produtores rurais, agroindústria e de alguns pesquisadores vinculados ao setor agrário. A pesquisa realiza uma revisão bibliográfica do tema e analisa notícias publicadas em diferentes jornais e dados estatísticos oficiais dos dois países.

Palavras-chave: Argentina, Brasil, empresas transnacionais, políticas públicas, soja.

\section{INTRODUCCIÓN}

Al largo de las últimas décadas, la soja se convirtió en la principal actividad agrícola en Brasil y Argentina, tanto en términos territoriales (superficie sembrada) como comercial (valor de exportación). La fuerte y rápida expansión de la soja y sus derivados dio origen a distintas interpretaciones para explicar las razones que influyeron en este crecimiento en ambos países. Diversas entidades representativas de los productores primarios, agroindustria y algunos investigadores vinculados al sector agrario atribuyeron a las políticas de liberalización económica y al espíritu empresario de los productores y demás actores de la cadena las razones principales del boom sojero en ambos países.

Otras interpretaciones destacaron que la expansión de la soja estuvo vinculada con el contexto de globalización económica, comercial e financiera, defendido e estimulado por los organismos internacionales (GILPIN, 2011); el aumento de la demanda de productos derivados de la soja (PIERRI, 2004; DU BOIS, TAN; MINTZ, 2008); la actuación de un pequeño número de grandes empresas transnacionales (WESZ JR., 2011; MURPHY; BURCH; CLAPP 2012; PIERRI, 2014); la presencia y intervención del Estado vía diferentes instrumentos de políticas públicas (HEREDIA; PALMEIRA; LEITE, 2010; DELGADO, 2012; FERNÁNDEZ, 2013); las transformaciones tecnológicas e socio-organizacionales (GUIBERT et al., 2011; GRAS; HERNÁNDEZ, 2013).

Este trabajo, partiendo de un enfoque histórico-político, procura evidenciar la expansión de la soja en Argentina y Brasil a partir de la influencia del factor externo (demanda y precio internacional), de las diferentes políticas públicas y de las grandes empresas transnacionales, más allá del distinto grado de espíritu empresario y del funcionamiento estricto de mecanismos de libre mercado para entenderlo. Parte en su análisis de las opiniones sobre la sojización realizado por los principales representantes de los productores de soja y de las agroindustrias a través de consultas a noticias publicadas en sus páginas institucionales y en periódicos de Argentina y Brasil.

Por otra parte, fue realizada una revisión bibliográfica en estudios que tratan del tema de este artículo, así como fueron consultadas fuentes estadísticas del Ministerio de Agricultura, Ganadería y Pesca (MAGyP), Bolsa de Cereales de Buenos Aires, Bolsa de Comercio de Rosario, Instituto Nacional de Estadística y Censos de Argentina (INDEC), Instituto Brasileño de Economía e Estadística (IBGE), Ministerio de la Agricultura, Ganadería y Abastecimiento (MAPA), Compañía Nacional de Abastecimiento (CONAB), Ministerio de Desarrollo, Industria y Comercio Exterior (MDIC), Asociación Brasileña de Industrias de Aceites Vegetales (ABIOVE), entre otros. El estudio comparado de la cuestión permite abordar aspectos como la estructura económica, el contexto y las políticas que fomentan el desarrollo en los dos países.

Primeramente, el trabajo evidencia las diferentes interpretaciones sobre la expansión de la soja en Brasil y Argentina. Después aborda la historia de la difusión del grano en los dos países, el mercado mundial y el "boom de la soja" en términos 
de volumen de producción, superficie sembrada, productividad y regiones productoras. En la secuencia gana destaque la influencia de las políticas públicas y de las empresas transnacionales en el proceso de sojización, cerrando con las Consideraciones Finales.

\section{INTERPRETACIONES SOBRE EL BOOM SOJERO EN BRASIL Y ARGENTINA}

En las últimas tres décadas se produjo un proceso de fuerte crecimiento de la producción de granos en Argentina y Brasil, que tuvo como principal protagonista al incremento de las cosechas la soja (Tabla 1). En Argentina se triplicó la producción total de granos y la soja, que solo representaba un 10\% hacia 1980/81 alcanzó más del $50 \%$ del total de las cosechas en la campaña 2014/15. En Brasil la producción de soja sobre el total de los granos fue de un $26 \%$ en 1981/82 llegando a representar un $46 \%$ en $2014 / 15$ (ver Tabla 1) (en términos de superficie sembrada pasó de $23 \%$ a $57 \%$ en el mismo periodo).

Por otra parte, las exportaciones de soja y derivados (aceite y harinas) representaban un $27,7 \%$ del total de exportaciones en 2014 en Argentina (INDEC, 2015) y un 14,6\% en Brasil en 2015 (MDIC, 2016), constituyendo un rubro fundamental en la obtención de divisas en ambos países. Brasil es líder mundial en las exportaciones de soja en grano y Argentina de aceite y harina de soja.

Tabla 1 - Evolución de la producción de granos* en Brasil y Argentina (años seleccionados) - millones de toneladas

\begin{tabular}{ccrrrrrrrr}
\hline País & Producto & $1980 /$ & $1985 /$ & $1990 /$ & $1995 /$ & $2000 /$ & $2005 /$ & $2010 /$ & $2014 /$ \\
& Maíz & 1981 & 1986 & 1991 & 1996 & 2001 & 2006 & 2011 & 2015 \\
\hline \multirow{6}{*}{ Argentina } & 12,1 & 7,6 & 10,5 & 15,3 & 14,4 & 23,8 & 33,8 \\
& Trigo & 7,8 & 8,7 & 10,9 & 9,4 & 15,9 & 12,5 & 15,9 & 13,9 \\
& Soja & 3,7 & 7,1 & 10,8 & 12,4 & 26,8 & 40,5 & 48,9 & 61,4 \\
& Girasol & 1,2 & 4,1 & 4,1 & 5,5 & 3,1 & 3,8 & 3,7 & 3,2 \\
& Sorgo & 7,6 & 4,1 & 2,2 & 2,1 & 2,9 & 2,3 & 4,5 & 3,1 \\
& Otros & 2,4 & 1,8 & 2,6 & 2,7 & 3,3 & 2,8 & 6,1 & 6 \\
& Total & 35,6 & 37,9 & 38,2 & 42,6 & 67,3 & 76,4 & 102,8 & 121,4 \\
\hline \multirow{6}{*}{ Brasil } & Arroz & 8,6 & 9,8 & 10 & 10 & 10,4 & 11,7 & 13,6 & 12,4 \\
& Poroto & 2,4 & 2,4 & 2,8 & 3 & 2,6 & 3,5 & 3,7 & 3,1 \\
& Maíz & 21,3 & 20,3 & 24,1 & 32,4 & 42,3 & 42,5 & 57,4 & 84,7 \\
& Soja & 15,5 & 13,2 & 15,4 & 23,2 & 38,4 & 55 & 75,3 & 96,2 \\
& Trigo & 2,2 & 5,6 & 3,1 & 3,2 & 3,2 & 4,9 & 5,9 & 5,5 \\
& Otros & 1,6 & 2,2 & 2,3 & 1,5 & 3,1 & 4,2 & 6,3 & 5,2 \\
& Total & 51,6 & 53,4 & 57,6 & 73,4 & 100,0 & 121,9 & 162,3 & 207,2 \\
\hline
\end{tabular}

Fuente: MAGyP (2016) y CONAB (2016).

*Total de granos: arroz, avena, cebada, centeno, colza, girasol, maíz, poroto, soja, sorgo y trigo.

La interpretación sobre lo que condicionó este rápido e impresionante desempeño de la soja son divergentes. Norberto Ras, presidente de la Academia Nacional de Agronomía en Argentina, expresó la influencia de la desregulación y privatización de la economía argentina instrumentada en los años 90 como principal causa del crecimiento agrícola ${ }^{3}$. En tanto Héctor Huergo, director del Suplemento

\footnotetext{
3 “La etapa que vivimos se inicia en 1989. Una transformación profunda de toda la política macroeconómica nacional aporta por lo menos tres características significativas para la innovación tecnológica en el sector rural: a) Un control administrativo riguroso que promete equilibrio fiscal, moneda estable, presión impositiva en disminución, apertura económica, mejores servicios y reducción del parasitismo y la burocracia; b) La devolución al sector agropecuario y a los productores de una ubicación protagónica en la economía nacional y la seguridad de no ser sometidos a discriminaciones odiosas; c) El afianzamiento del sector privado en toda
} 
Rural en el Diario Clarín afirmó, en el mismo sentido, que la revolución tecnológica llevada adelante en un marco de libertad económica por productores innovadores era la razón principal del boom sojero. Refiriéndose a Héctor Ordoñez, profesor de la Facultad de Agronomía/UBA señaló:

En los treinta años siguientes (posteriores a 1974) no hiciste más que prepararte día a día para elaborar el sueño de la Argentina Verde y competitiva. Estudiaste a Von Hayek y descubriste que democracia y libertad de mercado son fuentes de vida y crecimiento [...] En los pocos años (década de 1990) que duró la no discriminación, el sueño de la Argentina verde se convirtió en la Segunda Revolución de las Pampas. Que fue tan fuerte que cuando llegó esta segunda discriminación de las Pampas (a partir del 2002 cuando se reimplantan retenciones a las exportaciones de granos) la revolución tecnológica continuó más por convicción ideológica de los actores que por conveniencia económica ${ }^{4}$.

Gustavo Grobocopatel, el productor de mayor relevancia por la cantidad de hectáreas cultivadas, afirmó sobre los cambios organizacionales y tecnológicos en las explotaciones agrícolas y las políticas de los años 90:

Es cierto que hay ciento cincuenta mil productores menos, que se fundieron en la década pasada. O sea que la competitividad de la soja se hizo con sangre. No fue una fiesta. Y, ¿qué es la competitividad de la soja? Es la suma de innovaciones tecnológicas y organizacionales que pusimos en el campo durante los últimos quince años ${ }^{5}$.

En paralelo, en Brasil, el Ministerio de Agricultura, Ganadería y Abastecimiento, en su página institucional, afirmó que "o aumento da produtividade está associado aos avanços tecnológicos, ao manejo e eficiência dos produtores [...]. No cerrado, o cultivo da soja tornou-se possível graças aos resultados obtidos pelas pesquisas da Empresa Brasileira de Pesquisa Agropecuária (Embrapa), em parceria com produtores, industriais e centros privados de pesquisa". ${ }^{6}$ Por su parte, el Presidente de la Confederación de Agricultura y Ganadería de Brasil (CNA) señaló:

A moderna agropecuária do País, que teve início nos anos 70 do século passado, é um empreendimento essencialmente privado. O Estado teve sua parte, em especial na produção do conhecimento científico e tecnológico, por meio da excelência singular de nossas universidades rurais e da experiência pioneira da Embrapa, bem como na montagem de um sistema eficiente de crédito rural. Foi a iniciativa privada que transformou os campos do sul do Brasil e ocupou os vastos cerrados improdutivos que predominavam em grande parte de nosso território. Foi trabalho de pioneiros, portadores de experiência profissional na produção e capazes de empreender

\footnotetext{
la economía privatiza numerosos servicios y admite también la participación empresaria en sectores de la investigación, difusión y adopción de técnicas incorporadas en insumos, en capacitación u otros mecanismos" (Ras, 1994, p 23).

${ }^{4}$ http://edant.clarin.com/suplementos/rural/2006/04/08/r-00301.htm

${ }^{5}$ Grobocopatel en Revista Fortune, 15/09/2003, en Gras y Hernández (2009, p. 54).

${ }^{6} \mathrm{http}: / /$ www.agricultura.gov.br/vegetal/culturas/soja
} 
e assumir riscos tremendos. Povoaram grandes vazios, sem os confortos das cidades e sem a menor infraestrutura, numa aventura pessoal que merece justo registro na História moderna do Brasil. A eficiência do setor privado excedeu, em muito, a competência do Estado brasileiro. Assim, os resultados de grande parte da produção são afetados pela carência quase absoluta de infraestrutura.

En los relatos citados, el desempeño de la soja se atribuye a la iniciativa privada y al espíritu empresarial y pionero de los agentes implicados. Para ellos, el Estado tiene una actuación puntual (en el caso de Brasil principalmente vía Embrapa) y el contexto internacional y las empresas que articulan la cadena no ganan mucha notoriedad en el discurso.

La coincidente interpretación dominante en ambos países desecha otras que en el pasado explicaron el devenir el agro latinoamericano; en particular los aportes de la escuela estructuralista que expresaron la FAO, CEPAL y otras instituciones en los años 50 y 60 , que cifraban el atraso de la agricultura latinoamericana como resultado de la falta de inversión tecnológica y/o en la estructura de reparto de la tierra ${ }^{8}$. Tampoco toma en cuenta la vertiente explicativa histórico-estructural que planteó como problema principal de la agricultura de esta parte del mundo a la inserción dependiente de la agricultura de estos países respecto del mercado mundial. Autores representativos de esta corriente subrayaron que la estructura productiva de la agricultura de estos países es resultado de las necesidades del centro dominante en un proceso único de acumulación a nivel mundial; Garramon y Janvry (1976, p. 4) señalaron en efecto; "el centro modela a la periferia dominada, de modo que las contradicciones internas de la acumulación en la periferia creen relaciones externas necesarias que sean congruentes con las necesidades del centro".

Desde el enfoque histórico-estructural, la producción de soja debe incluirse en el sector de agricultura comercial ligada al mercado mundial, que convive en Latinoamérica con una agricultura familiar orientada al mercado interno; aquella orientada a brindar alimentos baratos al mundo en tanto la otra crea trabajo barato en lo interno. Miguel Teubal, autor representativo de esta corriente ${ }^{9}$, refiriéndose a la agricultura comercial afirmó que en las últimas décadas aumentó la dependencia respecto de los países capitalistas centrales que se materializa en el control de grandes empresas agroindustriales multinacionales que concentran la provisión de insumos y bienes de capital para el agro, la industrialización - en este caso de los granos - y los procesos de comercialización (TEUBAL 1979; TEUBAL; PALMISANO, 2015).

En síntesis, existen diferentes interpretaciones sobre la sojización en Argentina y Brasil. Algunos discursos - principalmente de las entidades representativas de los productores primarios y agroindustria, pero también de algunos investigadores vinculados al sector agrario - destacan la liberalización económica y el espíritu empresario de los productores (orientado en adherir a las innovaciones tecnológicas). En este texto procuramos problematizar esta interpretación "liberal-tecnológica-schumpeteriana", trayendo otros elementos para explicar el "boom sojero".

\footnotetext{
${ }^{7}$ http://www.senar.org.br/noticia/os-temores-do-campo.

${ }^{8}$ A nível individual, quizás los principales exponentes de la vertiente estructuralista fueron Raúl Prebish, Horacio Giberti, Celso Furtado y Paul Singer en ambos países.

${ }^{9}$ Un análisis de las distintas interpretaciones sobre la evolución del agro latinoamericano en Astori (1984).
} 


\section{HISTORIA DE LA DIFUSIÓN DE LA SOJA EN BRASIL Y ARGENTINA}

En Brasil, la soja llegó en 1882 desde Estados Unidos y tuvo una temprana difusión por parte del Estado en Bahía, San Pablo y Rio Grande del Sur (EMBRAPA, 2004) y se fomento su cultivo como forraje. En Argentina se inició su difusión a comienzos del siglo XX en la Escuela de Ganadería y Agricultura de la provincia de Córdoba y desde 1923 el Ministerio de Agricultura Nacional fomento su siembra (REMUSSI; PASCALE, 1973). Hasta 1950 la producción fue muy pobre en Argentina y Brasil y su incidencia en las exportaciones en ambos países fue inexistente, situación que coincide con una época en que el comercio mundial del grano era tan bajo que determinaba que no fuera incluido en los anuarios de la FAO referidos a productos alimenticios.

Luego de la $2^{\text {a }}$ Guerra Mundial, paulatinamente se incrementó la producción mundial, destinado al alimento animal en los Estados Unidos que a su vez se transformó hacia la década del 60 en el principal exportador mundial (casi monopolizando las ventas) que dirigió el grueso de las ventas a países de Europa occidental y Japón ${ }^{10}$.

El discreto y paulatino incremento del comercio mundial de soja originó que en Argentina en el año 1963 la Secretaria de Agricultura fomentara su cultivo garantizando un precio mínimo oficial a los productores y que en 1970 se creara la Comisión Permanente para el cultivo de Soja (integrada por el INTA, ministerios de agricultura de diversas provincias, Bolsa de Cereales y distintas universidades estatales) ${ }^{11}$. Un hecho anecdótico que ilustra el interés estatal en promover el cultivo fue la decisión en el año 1973 - de altísimos precios de los granos y posibilidades de exportación - de la Subsecretaria de Agricultura de enviar aviones de la Fuerza Aérea para transportar semilla de soja procedente de Estados Unidos con el propósito de aprovechar las oportunidades que se producían en el comercio mundial $^{12}$.

En Brasil, hasta la mitad del siglo XX, la soja fue utilizada como forraje del ganado lechero y en la crianza de porcinos en propiedades del sur del país. A partir de la década del 50 el Estado brindo incentivos para su siembra como cultivo secundario del trigo, fomentando la rotación entre ambos granos. Solo a partir de los años 60 la soja comenzó a establecerse como un cultivo importante, multiplicando su producción cinco veces: 206 mil toneladas en 1960 para 1 millón de toneladas en 1969 (EMBRAPA, 2004). Aun con una dimensión territorial menor en Argentina, la superficie de soja también creció en este periodo en el país, pasando de mil a 30 mil hectáreas (MAGyP, 2016).

En síntesis, hasta los años 1960 el fomento estatal para la producción de soja fue relativamente poco fructífero frente a un mercado mundial con exportaciones controladas monopólicamente por los Estados Unidos y con consumo prácticamente restricto a Europa y Japón.

\footnotetext{
${ }^{10}$ Datos estadísticos de comercio mundial de soja y razones del fuerte control del mismo por parte de los Estados Unidos, en Pierri (2004).

${ }_{11}^{11}$ Un mayor detalle de las políticas estatales de fomento en Remussi y Pascale (1977) y Pierri (2004 y 2007).

12 Refiriéndose a Armando Palau, Subsecretario de Agricultura 1973/75, "como habíamos asumido en mayo y el período de siembra es en primavera se acababa el período de siembra. Entonces consiguieron que la Fuerza Aérea les derivara dos aviones Hércules. Mandaron las naves a los Estados Unidos en un viaje relámpago, se cargo y volvió con las semillas. Una parte era para multiplicarla pero fundamentalmente para venderla, lo importante era difundirla entre los productores", Horacio Giberti, Secretario Nacional de Agricultura y Ganadería 1973/75, entrevista en Ramirez, Diego (2011, p. 461).
} 


\section{MERCADO MUNDIAL DE SOJA Y DERIVADOS (1960/2010)}

Durante y en la primera década posterior al fin de la $2^{\text {a }}$ Guerra Mundial el mercado mundial granario se modificó sustancialmente; se estancó el volumen de intercambios, y los países de Europa occidental y los Estados Unidos adoptaron políticas de intervención cuyas manifestaciones más significativas fueron el Plan Marshall y las europeas destinadas a conseguir el autoabastecimiento de alimentos mediante fuertes subsidios a sus agricultores. En ese contexto, un país estructuralmente exportador de granos como Argentina sufrió una disminución importante en su participación en el comercio mundial, en tanto Brasil, con una mayor porción de la producción destinada al mercado interno, tuvo un estancamiento menor.

A partir de la década del 60 comenzó paulatino crecimiento de la producción que se aceleró a partir de los extraordinarios aumentos de precio de las materias primas entre 1972 y 1974 y el aumento de la demanda internacional de granos, entre ellos de soja y derivados. El fortalecimiento de la soja ocurrió por la reducción y/o estancamiento de la producción de granos en algunos importantes países (como China y Rusia) y por el paulatino aumento del consumo de alimentos en otros del mundo en desarrollo. Por otra parte la falla en la pesca de anchoa en el Perú (donde se producía la harina que se utiliza ampliamente en la fabricación de alimentos para animales), presionaron a la suba a los precios internacionales, en tanto la decisión de los gobiernos de los Estados Unidos en 1979 y 1980 de practicar el bloqueo de ventas de granos a Irán y la URSS y en 1981 de abandonar parte de la política de subsidios a los productores y a la exportación de granos ${ }^{13}$ aumentaron significativamente las oportunidades de participar en ese mercado mundial a otros países como Argentina y Brasil (EMBRAPA, 2004; PIERRI, 2014).

Desde 1980 a 2010 el comercio mundial de soja y sus derivados fue largamente el que más creció en relación al de otros granos (Tabla 2). Los incrementos de trigo (algo más del 40\%) y maíz (aprox. 20\%) fueron superados ampliamente por el del poroto y sus derivados, que crecieron en conjunto más del $300 \%$. Es en ese rubro de exportación que Brasil y Argentina tuvieron oportunidades de crecimientos de sus ventas a la par que perdía fuerza el monopolio de Estados Unidos en las exportaciones y el monopsonio de Europa y Japón en las importaciones.

\footnotetext{
${ }^{13}$ El boicot de ventas de granos a la URSS y el abandono de subsidios a la producción y exportación de granos dispuestos por Reagan en 1981 se mantuvieron hasta 1985, cuando a partir de grandes movilizaciones de farmers endeudados el presidente republicano abandono el bloqueo a la URSS y retornó a la política de subsidios a la agricultura provocando un descenso en los precios internacionales.
} 
Tabla 2 - Evolución de las exportaciones mundiales (millones de toneladas) productos y años seleccionados

\begin{tabular}{|c|c|c|c|c|c|c|}
\hline Año & Trigo & Maíz & Soja & $\begin{array}{l}\text { Aceite } \\
\text { soja }\end{array}$ & $\begin{array}{l}\text { Harina } \\
\text { Soja }\end{array}$ & $\begin{array}{l}\text { Total soja y } \\
\text { derivados }\end{array}$ \\
\hline 1980 & 90,1 & 80,3 & 26,8 & 3,2 & 17,8 & 47,9 \\
\hline 1981 & 95,5 & 78,7 & 26,2 & 3,5 & 20,1 & 49,9 \\
\hline 1982 & 95,7 & 69,6 & 28,9 & 3,4 & 20,1 & 51,4 \\
\hline 1989 & 97,8 & 77,4 & 23,6 & 3,7 & 25,8 & 53,3 \\
\hline 1990 & 98,6 & 72,1 & 25,8 & 3,7 & 26,2 & 55,5 \\
\hline 1991 & 108 & 66,1 & 27,2 & 3,6 & 26,7 & 57,5 \\
\hline 1999 & 114,5 & 78,7 & 40,3 & 8,1 & 38,9 & 87,3 \\
\hline 2000 & 117,2 & 82,3 & 47,3 & 7,2 & 37,2 & 91,7 \\
\hline 2001 & 113,7 & 83,8 & 56,9 & 8,5 & 43,4 & 108,8 \\
\hline 2008 & 116,4 & 98,2 & 78,7 & 10,4 & 56,6 & 145,7 \\
\hline 2009 & 143,2 & 83,9 & 76,8 & 9,1 & 52,7 & 138,6 \\
\hline 2010 & 134,2 & 93,1 & 92,7 & 8,7 & 55,6 & 157,1 \\
\hline
\end{tabular}

Fuente: Faostat (2014).

La exportación mundial del grano pasó de 4 millones en 1960 a 91 millones de toneladas en 2011 (2.000\% de crecimiento). Al final de la serie, Brasil compite con Estados Unidos como principal exportador y Argentina, con un porcentaje menor, pero destacado. Las ventas de aceite de soja también tuvieron un aumento muy significativo en los últimos cincuenta años (2.460\%). Argentina se ha consolidado como el principal exportador (un 45\% del valor total en 2011), seguido por Brasil $(17,4 \%)$ y los EE.UU. (10\%). La harina fue el producto que tuvo el mayor crecimiento en el complejo de la soja entre 1961 y 2011 (5.360\%) (Tabla 3).

Tabla 3 - Exportaciones del complejo soja en toneladas (1961-2011)

\begin{tabular}{|c|c|c|c|c|c|c|}
\hline \multirow{2}{*}{ Países } & \multicolumn{6}{|c|}{ Soja en grano } \\
\hline & 1961 & 1971 & $1981^{\circ}$ & 1991 & 2001 & 2011 \\
\hline Argentina & 0 & 0 & 2.215 .609 & 4.431 .458 & 7.364 .885 & 10.820 .030 \\
\hline Brasil & 73.270 & 213.426 & 1.449 .729 & 2.020 .437 & 15.675 .543 & 32.985 .562 \\
\hline EEUU & 3.634 .190 & 11.521 .030 & 21.859 .728 & 17.610 .576 & 28.933 .830 & 34.310 .514 \\
\hline D+ países & 465.973 & 603.638 & 693.914 & 3.128 .831 & 4.985 .643 & 12.905 .373 \\
\hline Total & 4.173 .433 & 12.338 .094 & 26.218 .980 & 27.191 .302 & 56.959 .901 & 91.021 .479 \\
\hline \multirow{2}{*}{ Países } & \multicolumn{6}{|c|}{ Aceite de soja } \\
\hline & 1961 & 1971 & 1981 & 1991 & 2001 & 2011 \\
\hline Argentina & 0 & 0 & 69.886 & 1.246 .131 & 3.338 .214 & 4.416 .541 \\
\hline Brasil & 0 & 6.661 & 1.281 .267 & 512.218 & 1.651 .526 & 1.741 .413 \\
\hline EEUU & 273.261 & 778.433 & 797.746 & 452.044 & 681.173 & 1.000 .168 \\
\hline D+ países & 117.331 & 547.916 & 1.340 .451 & 1.407 .620 & 2.854 .082 & 2.845 .723 \\
\hline Total & 390.592 & 1.333 .010 & 3.489 .350 & 3.618 .013 & 8.524 .995 & 10.003 .845 \\
\hline \multirow{2}{*}{ Países } & \multicolumn{6}{|c|}{ Harina de soja } \\
\hline & 1961 & 1971 & 1981 & 1991 & 2001 & 2011 \\
\hline Argentina & 0 & 0 & 520.530 & 6.000 .466 & 14.624 .681 & 26.832 .024 \\
\hline Brasil & 33.000 & 901.404 & 8.891 .373 & 7.488 .583 & 11.270 .730 & 14.355 .169 \\
\hline EEUU & 614.390 & 4.086 .414 & 6.344 .021 & 5.242 .349 & 6.932 .023 & 6.701 .303 \\
\hline D+ países & 541.889 & 1.290 .168 & 4.399 .150 & 8.050 .752 & 10.604 .138 & 17.018 .511 \\
\hline Total & 1.189 .279 & 6.277 .986 & 20.155 .074 & 26.782 .150 & 43.431 .572 & 64.907 .007 \\
\hline
\end{tabular}

Fuente: Faostat (2014).

En lo que respecta a las importaciones, Europa fue el principal destino de la soja, con más del $55 \%$ de las compras hasta principios de los años noventa. A partir 
de esa década (los 90) Asia amplía de manera extraordinaria su demanda, triplicando en solo 20 años el volumen de sus compras, dando cuenta de las tres cuartas partes de las importaciones en 2011 (Tabla 4). Este resultado se debe principalmente a China, que adquiere un $60 \%$ de las importaciones mundiales muestra una producción nacional insuficiente debido a la menor expansión de las áreas en producción y su baja productividad en tanto el aumento de la población y urbanización, el crecimiento económico, los cambios en los patrones de consumo junto a las decisiones estatales de privilegiar otras producciones de alimentos, que ocupen mayor cantidad de mano de obra, implicaron aquella necesidad de aumento de importaciones (WILKINSON; WESZ JR., 2013).

En las importaciones de aceite de soja ocurrió un movimiento similar a lo descripto anteriormente, con un incremento de las compras en Asia y la reducción del peso relativo de Europa, alcanzando el $43 \%$ y el $16,4 \%$ en 2011 , respectivamente. Sin embargo, en este producto hay un mayor peso de África y América, ambos con un $20 \%$. La harina, a su vez, sigue siendo adquirida principalmente por Europa (46,8\% en 2011$)$, pero en niveles mucho más bajos en la década de 1970, cuando superaba el $90 \%$ (Tabla 4).

Tabla 4 - Importaciones del complejo soja en toneladas (1961-2011)

\begin{tabular}{|c|c|c|c|c|c|c|}
\hline \multirow{2}{*}{ Países } & \multicolumn{6}{|c|}{ Soja en grano } \\
\hline & 1961 & 1971 & 1981 & 1991 & 2001 & 2011 \\
\hline África & 11.917 & 185 & 24.569 & 36.124 & 726.080 & 1.642 .597 \\
\hline América & 335.334 & 617.372 & 2.617 .095 & 2.498 .418 & 7.915 .587 & 5.206 .566 \\
\hline Asia & 1.491 .769 & 4.349 .657 & 7.525 .271 & 9.195 .931 & 27.962 .623 & 68.287 .127 \\
\hline Europa & 2.250 .954 & 7.723 .346 & 16.067 .256 & 14.659 .290 & 20.761 .973 & 15.675 .745 \\
\hline Oceanía & 5 & 10.822 & 41.666 & 78.468 & 794 & 1.942 \\
\hline Total & 4.089 .979 & 12.701 .382 & 26.275 .857 & 26.468 .231 & 57.367 .057 & 90.813 .977 \\
\hline \multirow{2}{*}{ Países } & \multicolumn{6}{|c|}{ Aceite de soja } \\
\hline & 1961 & 1971 & 1981 & 1991 & 2001 & 2011 \\
\hline África & 39.271 & 193.004 & 463.144 & 345.600 & 1.110 .381 & 2.056 .023 \\
\hline América & 49.055 & 121.856 & 436.081 & 591.210 & 1.282 .285 & 2.045 .783 \\
\hline Asia & 100.723 & 445.254 & 1.470 .269 & 1.535 .381 & 4.305 .711 & 4.388 .048 \\
\hline Europa & 313.159 & 538.691 & 840.924 & 906.049 & 1.443 .991 & 1.676 .496 \\
\hline Oceanía & 2.731 & 9.840 & 36.147 & 52.098 & 33.597 & 36.049 \\
\hline \multirow[t]{2}{*}{ Total } & 504.939 & 1.308 .645 & 3.246 .565 & 3.430 .338 & 8.175 .965 & 10.202 .399 \\
\hline & \multicolumn{6}{|c|}{ Harina de soja } \\
\hline Países & 1961 & 1971 & 1981 & 1991 & 2001 & 2011 \\
\hline África & 780 & 10.936 & 323.680 & 881.133 & 2.468 .778 & 4.192 .746 \\
\hline América & 224.707 & 402.520 & 1.247 .116 & 2.322 .531 & 4.525 .972 & 8.379 .869 \\
\hline Asia & 73.320 & 140.724 & 1.338 .938 & 3.960 .362 & 10.855 .517 & 20.616 .172 \\
\hline Europa & 929.715 & 5.523 .952 & 16.131 .388 & 19.056 .259 & 24.823 .414 & 29.743 .032 \\
\hline Oceanía & 0 & 30.043 & 21.419 & 61.383 & 234.290 & 661.265 \\
\hline Total & 1.228 .522 & 6.108 .175 & 19.062 .541 & 26.281 .668 & 42.907 .971 & 63.593 .084 \\
\hline
\end{tabular}

\section{EL "BOOM DE LA SOJA": CAMBIOS EN EL VOLUMEN DE PRODUCCIÓN, SUPERFICIE SEMBRADA, PRODUCTIVIDAD Y REGIONES PRODUCTORAS}

La fuerte demanda internacional por harina y aceite presionaron los precios internacionales de la soja (USDA, 2014) y estimularon en ambos países el cultivo de variedades más adaptadas y con viabilidad técnica para la rotación con maíz, trigo o girasol. Mejoras en los sistemas de transporte y comunicaciones y fortalecimiento de la capacidad de procesamiento de oleaginosas y, en el caso de Brasil, aumento de 
la demanda interna con la creciente urbanización y el cambio de los hábitos alimentarios de la población facilitaron la expansión (CASTRO, 1996; EMBRAPA, 2004; PIERRI, 2006).

En Brasil la superficie cultivada con soja pasó de 1,3 a 8,8 millones de hectáreas en la década de 1970, y la producción saltó de de 1,5 millones a más de 15 millones de toneladas (Figura 1). En Argentina el crecimiento fue aun más impresionante: el área se incrementó desde las de 37 mil a las 2 millones de hectáreas y la producción de 58 mil a 3,5 millones de toneladas entre 1970 y 1980 (Figura 2). En los años 80 hubo una mayor estabilidad en la expansión del cultivo en particular en Brasil -, motivado principalmente por la caída de los precios internacionales y la crisis económica nacional (WESZ JR., 2014).

Figura 1 - Área sembrada (en mil hectáreas) e producción de soja (en mil toneladas) en Brasil (1971/72 - 2014/15)

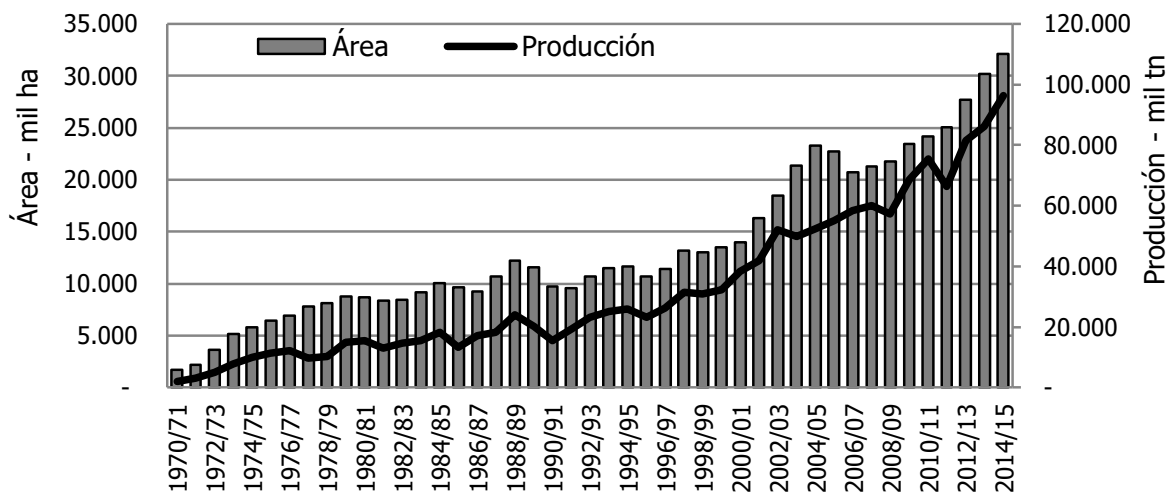

Fuente: Conab (2016).

Figura 2 - Área sembrada (en mil hectáreas) e producción de soja (en mil toneladas) en Argentina (1970/71 - 2014/15)

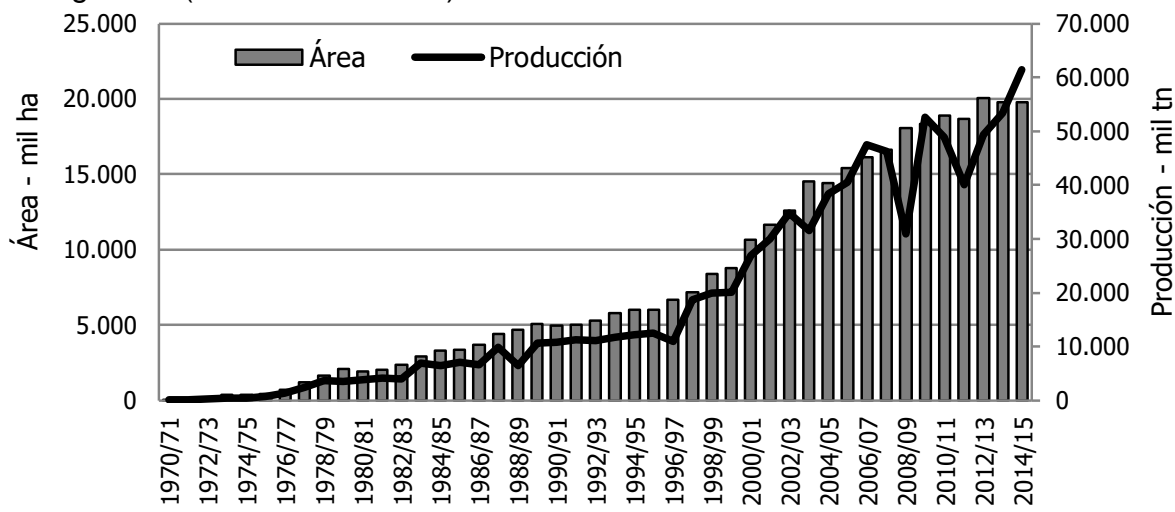

Fuente: MAGyP (2016)

Distintos autores han subrayado la importancia que en los años 70 y 80 tuvo la llamada "modernización de la agricultura", que se caracterizó, entre otras cosas, por: la mejora genética de las semillas, aumentando el uso de maquinaria, producción y difusión de nuevos insumos (pesticidas, fertilizantes sintéticos, etc.), 
especialización productiva, maximización de los factores de producción, introducción del capital no agrícola y implementación de políticas públicas y privadas para la expansión del modelo agroexportador (KAGEYAMA et al., 1990; GRAS; HERNÁNDEZ, 2013).

En el caso de la producción de soja a partir de la campaña 1995/96 hubo un gran aumento de la superficie sembrada y de la producción en Brasil y Argentina, que se hizo conocido como "boom de la soja", "sojización", "oleaginización de la agricultura" y/o "pampeanización" de otras regiones en el país del sur (PENGUE, 2004; PIERRI, 2006; GUIBERT et al., 2011; WESZ JR., 2014). En Argentina, el área y la producción se triplicaron desde 1995/96 hasta 2014/15. En los últimos años la superficie se ha mantenido cercana de las 20 millones de hectáreas y la producción llegó a superar las 60 millones de toneladas (MAGyP, 2016).

En Brasil el área se triplicó y la producción se cuadruplicó de 1995/96 hasta 2014/15. Sin embargo, no hubo un crecimiento casi ininterrumpido de la superficie como en Argentina, porque dejan de ser cultivados dos millones de hectáreas de soja de 2006 a 2007, pero en los años siguientes hubo una nueva expansión, llegando a 96,2 millones de toneladas y 32,1 millones de hectáreas (un aumento del $65 \%$ y $55 \%$, respectivamente de $2006 / 07$ a 2014/15) (CONAB, 2016). En ambos países el fuerte aumento en las hectáreas cultivadas se realizó sobre aéreas tradicionales de otras producciones de granos o ganaderas, sobre el desmonte de áreas vírgenes o mediante la generalización del doble cultivo anual.

En términos de regiones productoras se percibe la intensificación del cultivo en las regiones más "tradicionales", como el sur y sudeste de Brasil (estados de Rio Grande do Sul, Santa Catarina, Paraná, São Paulo e Minas Gerais) y la pampa argentina (provincias de Buenos Aires, Santa Fe e Córdoba). Concomitantemente, hay una fuerte expansión para el Norte de los dos países, principalmente en las provincias argentinas de Chaco, Santiago del Estero, Salta, Formosa y Entre Ríos; y en los estados brasileños de Mato Grosso, Rondônia, Goiás, Pará, Maranhão, Tocantins, Piauí y Bahía ${ }^{14}$, como es evidente en las Figuras 3 y 4 . En cuanto la región "tradicional" controlaba $60 \%$ del área en Brasil y $90 \%$ en Argentina en 1995/96, actualmente representa $40 \%$ y $75 \%$, respectivamente.

Debe destacarse que las razones de los volúmenes de producción presentan algunas diferencias comparando la evolución en los dos países. En Argentina los rendimientos por hectárea fueron sensibles, pero no extraordinarios, se incrementaron desde los $2.048 \mathrm{Kg} / \mathrm{ha}$ en promedio en el quinquenio 1980/85 a unos $2.645 \mathrm{Kg} / \mathrm{ha}$ en promedio a nivel nacional entre 2005 y 2010 (29,1\% de incremento). En tanto Brasil, en la primera mitad de los 80 , tenía una productividad más baja que Argentina $(1.700 \mathrm{Kg} / \mathrm{ha})$, pero esta aumentó decididamente en tiempos recientes $(2.723 \mathrm{Kg} / \mathrm{ha}$ en promedio entre 2005 y 2010). Debe destacarse que en Argentina, los rendimientos en las tradicionales provincias agrícolas y de mayor producción del grano (Santa Fe, Buenos Aires, Córdoba y Entre Ríos) son solo algo mayores en las dos primeras que el promedio nacional. En Brasil, en promedio entre 2005 y 2010 , los rendimientos más elevados ocurrieron en el centro-norte del país (Mato Grosso, Goiás, Rondônia, Pará, Roraima), con más de $2.800 \mathrm{Kg} / \mathrm{ha}$, en cuanto el sur se quedo con una media debajo de $2.600 \mathrm{Kg} / \mathrm{ha}$ (CONAB, 2016; MAGyP, 2016).

Los rendimientos del último lustro en ambos países son solo levemente inferiores que los alcanzados en el otro gran productor mundial, los Estados Unidos

\footnotetext{
${ }^{14}$ Estos últimos cuatro estados, que se quedaron conocidos como Matopiba (acrónimo formado por las iniciales), son actualmente la principal área de expansión de la frontera agrícola de Brasil (Vieira Filho, 2016), aun que produzcan $12 \%$ de la soja en $2014 / 15$ - Mato Grosso es el mayor estado productores del grano, con $28 \%$, seguido por Paraná y Rio Grande do Sul, con16\% cada (Conab, 2016).
} 
donde oscilaron entre los $2.671 \mathrm{~kg} / \mathrm{ha}$ y los $3.024 \mathrm{~kg} / \mathrm{ha}$ entre 2005 y 2009 , dato que reafirma la relativa alta paridad de rendimientos derivado de la homogeneidad de los sistemas productivos en los distintos países y la alta adaptabilidad y rusticidad del cultivo.

Figura 3 - Área sembrada con soja por microrregión en Brasil
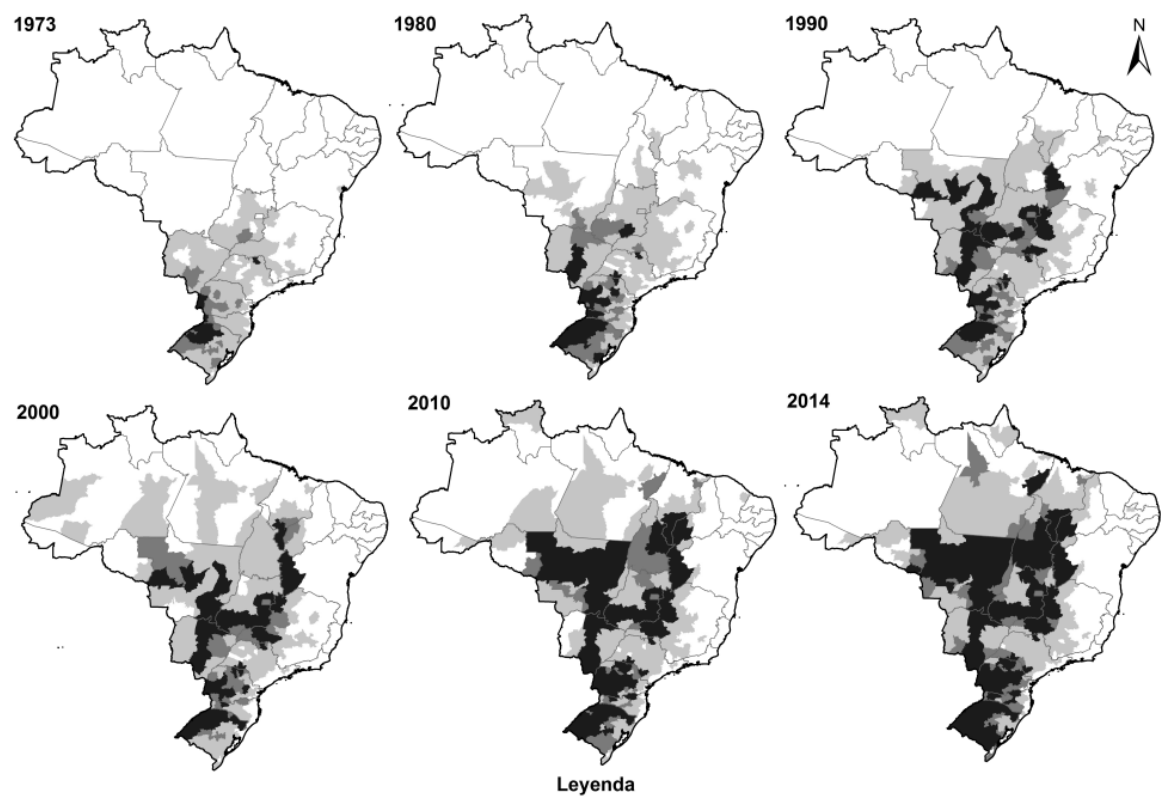

$$
\square \text { Sin soja } \square<30 \text { mil ha } \quad>30 \mathrm{mil}<75 \mathrm{mil}
$$

$>75$ mil ha

Fuente: Produção Agrícola Municipal (IBGE, 2016). Elaboración de los autores. 
Figura 4 - Área sembrada con soja por departamento en Argentina
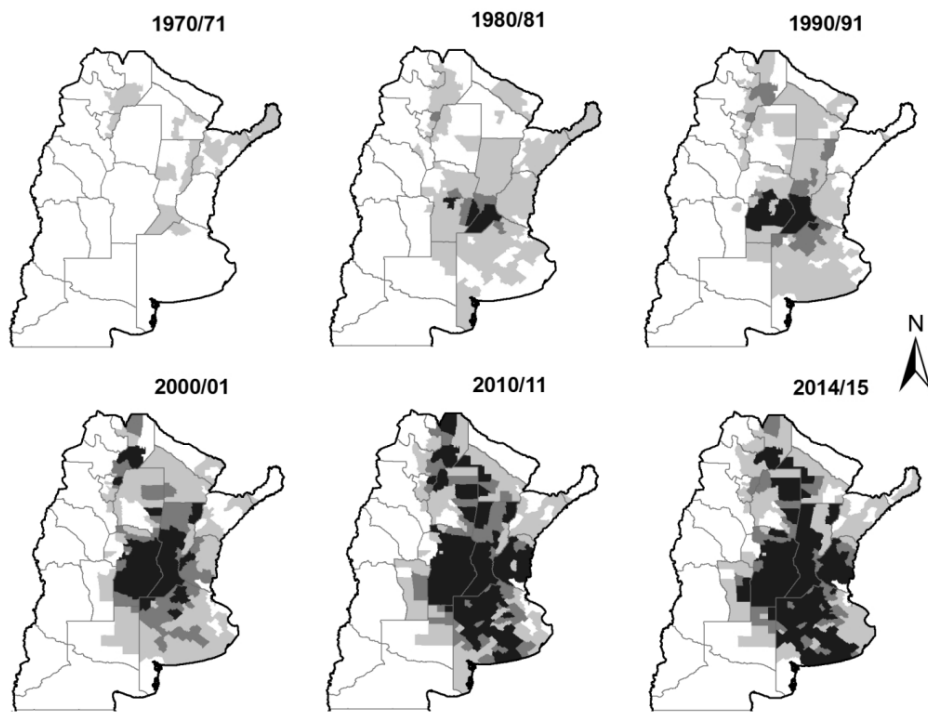

Leyenda

Sin soja

$<30$ mil ha

$>30 \mathrm{mil}<75 \mathrm{mil} \mathrm{ha}$

$>75$ mil ha

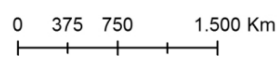

Fuente: MAGyP (2016). Elaboración de los autores.

\section{INFLUENCIA ESTATAL EN EL “BOOM SOJERO”}

La acción estatal fue fundamental en inducir y modelar características principales del boom sojero. En Argentina, una de las medidas más importantes fueron la disolución en 1991 de la Junta Nacional de Granos ${ }^{15}$, la eliminación de retención a la exportación de granos y la modificación del sistema portuario nacional mediante la ley 24.093 de 1992 que transfirió a las provincias la potestad sobre su administración y permitió la privatización en su operación. El nuevo marco legal posibilitó que, en muy breve tiempo, grandes empresas transnacionales construyeran terminales portuarias bajo la forma jurídica de puertos industriales ${ }^{16}$, donde localizaron algunas de las más grandes plantas de producción de aceite del mundo. En el mismo sentido, la legislación de la década recortó derechos laborales a empleados portuarios ${ }^{17}$ y estuvo orientada a limitar los derechos de protestas de los trabajadores en ese ámbito específico.

\footnotetext{
${ }^{15}$ Mediante los decretos 2284 del 31/10/1991 y 2486 del 26/11/1991 el Poder Ejecutivo dispuso la disolución de la Junta Nacional de Granos.

${ }^{16}$ La ley de Actividades Portuarias 24093 y el Decreto ley 769/93 establecen e4l marco legal de estos puertos privados que incluyen la actividad industrial.

${ }^{17}$ El decreto 817/92 de desregulación marítima y la reglamentación de la ley 24093 mediante el decreto 769/93 suspendieron los convenios colectivos del sector, establecieron la libre contratación, la eliminación ajustes salariales automáticos y los derechos "que conspirase contra la productividad laboral".
} 
La estrecha relación entre política estatal y grandes empresas se expresó también en la decisión de efectuar el dragado del Río Paraná y concesionar el mantenimiento de esa vía fluvial exactamente hasta el punto donde se encuentra el último de aquellos puertos industriales. En enero de 1994 se licitó la modernización, ampliación, operación, mantenimiento y señalización de la hidrobia del río Paraná entre su kilómetro 584 y su desembocadura en el Río de la Plata, comprometiendo a los concesionarios a llevar el calado de la vía a 28 y 32 pies en etapas sucesivas y otorgándoles al derecho de cobro de peaje y a percibir una subvención del Estado Nacional de 40 millones de dólares anuales.

Otras medidas que dieron impulso al modelo sojero fueron la creación en 1991 del Instituto Nacional de Semilla (INASE) y la Comisión Nacional Asesora en Biotecnología Agropecuaria (CONABIA) (Resolución SAGyP 124/91). Finalmente, en octubre de 1994 se promulgó la Ley 24.376 que ratificó la incorporación de Argentina a las Actas de creación de la Unión de Protección de Obtentores Vegetales (UPOV) y adhirió a su convenio de $1978^{18}$. Ese marco fue de vital importancia para habilitar en el año 1996 el uso de la semilla de soja genéticamente modificada (SojaGM) patentada en Estados Unidos por la empresa Monsanto, cuando su uso era resistido y prohibido en toda Europa y países de América del Sur ${ }^{19}$.

En Brasil, además de numerosos instrumentos impulsados durante la dictadura militar (1964-1985) ${ }^{20}$, desde el Plan Real se adoptó una política neoliberal con la atracción de capital extranjero, la liberalización del comercio y la privatización (CARNEIRO, 2002). En el sector del transporte fue la privatización de los ferrocarriles en 1996 y 1997, los cuales fueron comprados por las empresas que eran sus clientes. En cuanto a la infraestructura portuaria, la Empresa de Puertos Brasil (Portobras) se abolió en 1990 y en 1993 se aprobó la Ley de Modernización de los Puertos, que autorizó al gobierno federal para delegar a los estados y municipios la administración y operación de los puertos públicos, que podían transferir estos servicios al sector privado (MONTES; REIS, 2011). En 2013 se aprobó la Ley 12.815, que, entre otras cosas, permitió que "cualquier empresa que tiene los derechos de la zona costera puede requerir la autorización para la implantación de terminales de uso privado" (BARROS, 2014, p. 39), incluyendo la posibilidad de construir terminales industriales. La normativa posibilitó que Bunge, Cargill, ADM, Dreyfus y Amaggi hicieron grandes inversiones en logística, sobre todo en la construcción y ampliación de puertos, canales y ferrocarriles que conectan las regiones productoras de soja con mercado internacional.

\footnotetext{
18 Las decisiones de los años '90 establecieron derechos de propiedad sobre la venta de las semillas patentadas pero no declinaron el llamado "privilegio del agricultor" sobre el uso gratuito de la semilla por ellos cultivada.

${ }_{19}$ Un análisis sobre la legislación de semilla en Estados Unidos y en la Argentina en Pierri, José y Abramovsky, Marcelo, Legislaciones de patentes de semilla y uso de insumos en la producción de soja en Argentina y Estados Unidos 1990/2006. Realidad Económica № 244, junio. 2009.

20 Durante los años 80 y 90, la producción de soja se benefició de diferentes políticas públicas en Brasil: Sistema Nacional de Crédito Rural (SNCR), que proporcionó recursos subsidiados para diferentes inversiones; Política de de Garantía de Precios Mínimos (PGPM), que establecía un precio base antes de la siembra; fomento a la innovación tecnológica, con destaque a la adaptación de cultivares a través de la investigación llevada a cabo por la Embrapa (Empresa Brasileña de Investigación Agropecuaria); modernización de las industrias de transformación y segmentos de la industria proveedores de insumos y máquinas con potencial de exportación, que recibió enorme carga de incentivos y subsidios; la creación de nuevos canales de distribución y el establecimiento de nuevos corredores de exportación; subvenciones a la exportación en forma de exenciones, créditos fiscales y las tasas de interés favorecidos (KAGEYAMA et al., 1990; CASTRO, 1996; LEITE, 1998; EMBRAPA, 2004). El gobierno militar también promovió la ocupación del Cerrado y la Amazonia, central para la expansión de la frontera agrícola en estas áreas, que jugó un papel decisivo en el avance de la soja en el norte del país (FERNÁNDEZ, 2007).
} 
También fue importante en Brasil la Ley de Patentes (9.279 de 1996), que extendió los derechos monopólicos de propiedad intelectual a los procesos relacionados con la alimentación, y la Ley de Protección de Cultivares (9.456 de 1997), que liberó la apropiación privada de las variedades de semillas por las empresas de mejoramiento genético. Ambas promovieron una tendencia a la concentración en el sector de la producción de semillas por las empresas transnacionales perdiendo participación en el sector público. Además, se aprobó la Ley de Bioseguridad (11.105 de 2005), que permite el uso comercial de organismos genéticamente modificados y el cobro de regalías por las empresas (en especial Monsanto) (WILKINSON; CASTELLI, 2000; PESSANHA; WILKINSON, 2005; SCHIOSCHET; PAULA, 2008; SILVA MAZON, 2010).

Las políticas de organización y protección de los mercados agrícolas también sufrieron cambios bruscos en Brasil. En 1996 se produjo el desmantelamiento de los precios mínimos y de los estoques (stocks) por parte del Estado. El mercado abierto favoreció la importación de mercancías en virtud de los regímenes de tarifas bajas o nulas, tipo de cambio sobrevaluado y abundante liquidez internacional. Por lo tanto, el papel del gobierno en la formación del precio y regulación de los stocks de granos ha sido sustituida gradualmente por herramientas privadas para apoyar la comercialización, cuya característica principal es la garantía de precio de compra sin stocks (DELGADO; CONCEIÇÃO, 2005).

Otra iniciativa muy importante para la soja fue la reducción del impuesto para exportación, con la promulgación de la Ley Kandir (1996). Con anterioridad la soja tenía un impuesto de exportación de 13\% y el aceite y harina de $10 \%$. Después de la aprobación de la Ley Kandir, el impuesto de las exportaciones in natura fueron abandonados (0\%) y, en el caso de los productos transformados existen diferencias: 1) cuando el producto se cultiva y se procesa en el mismo estado, no hay impuestos y 2) cuando el producto se cultiva en un estado y es industrializados en otro, hay impuesto del $12 \%$. Esto permitió, por un lado, una mayor competitividad de las exportaciones de productos agrícolas brasileños (que no pagaron los impuestos sobre las ventas al mercado externo) y, en segundo lugar, redujo significativamente la viabilidad de la producción agroindustrializada. Por otra parte, aproximó las áreas de producción y procesamiento (WESZ JR., 2011). Los resultados de la Ley Kandir fueron inmediatos: la soja exportada en grano pasó de 5\% en 1996 a 30\% en 1998 (porcentaje de la producción cosechada), reduciendo lo que fue enviado a la industria (ABIOVE, 2016).

El crédito rural público ofrecido a los agricultores también mostró un crecimiento significativo desde el advenimiento del Plan Real, con una expansión prácticamente ininterrumpida hasta el período actual. De 1996 a 2014, el volumen de los fondos aumentó de $R \$ 26$ billones a $R \$ 166$ billones (valores constantes de 2014). Además de una mayor oferta de recursos, se produjo la creación de nuevas líneas de crédito y la reducción en las tasas de interés (LEITE; WESZ JR., 2014). La soja es el cultivo que recibe más recursos, llegando a 43\% en 2015 (BCB, 2016). Delgado (2012) señala que hay una parte del crédito que está subvencionado, porque en casi todos los contractos disfrutan de un interés inferior al del mercado (interés del 6,75\% en 2009 para una tasa de mercado que era el doble).

Otro instrumento que afectó directamente al mercado de la soja fue la creación del Programa Nacional de Producción y Uso de Biodiesel (PNPB) en 2004, lo que determinaba la mezcla obligatoria del $5 \%$ de biodiesel en el diesel convencional, que en 2014 se extendió a 7\% (RATHMANN; SILVEIRA; SANTOS, 2008; OLIVEIRA; REYS, 2009). EI PNPB ha utilizado la soja como materia prima principal - arriba del $75 \%$ en los últimos años (ANP, 2015). Actualmente, de acuerdo con Abiove (2016), 27\% de aceite de soja brasileño se utiliza para la producción de 
biodiesel. En este sentido, es un mercado importante que se ha creado y definido por el Estado.

El conjunto de políticas, programas, acciones e instrumentos de política desarrollado, implementado y/o mediado por el Estado en Brasil y Argentina demuestra el papel clave del sector público en la transformación de la agricultura, en especial la cadena de producción de la soja. Más de relativizar el papel del sector privado, se reconoce la importancia de las políticas públicas en la promoción del modelo agroexportador en un contexto de globalización de la economía, del comercio y de las finanzas, que es impulsado por organismos internacionales.

\section{LAS EMPRESAS TRANSNACIONALES: CONCENTRACIÓN Y EXTRANJERIZACIÓN}

Los procesos de globalización de los mercados y la liberalización económica en Brasil y Argentina a partir de 1990 causaron una mutación en la estructura de capital de las empresas, con la expansión de la inversión extranjera directa y el aumento del número de fusiones y adquisiciones. Además de la intensificación de los procesos de desnacionalización de las firmas, hubo un aumento en la internacionalización de los mercados, la concentración empresarial y centralización del capital. Es importante reconocer, como advierten Pierri (2006) y Flexor (2006), no son fenómenos nuevos, pero lo que ocurrió fue la aceleración de las situaciones que ya estaban presentes en las décadas anteriores y ya no son más tímidas y minoritarias después de la liberalización del comercio y la atracción de capital internacional.

En Brasil y Argentina la industria de tractores, cosechadoras e implementos agrícolas fue sometida a un proceso de concentración entre 1990 y 2012, siguiendo la tendencia mundial. Actualmente el mercado está dominado por tres empresas transnacionales: $\mathrm{CNH}$ (con las marcas Case y New Holland), AGCO (con las marcas AGCO Allis, Valtra y Massey Ferguson) y John Deere. En Brasil, en 2014, la producción de tractores se encontraba bajo el control casi total de AGCO (47\%), $\mathrm{CNH}(26 \%)$ y John Deere (20\%). El segmento de cosechadoras está aún más concentrada, con una fuerte presencia de $\mathrm{CNH}(47 \%)$ y John Deere (39\%), dejando el 15\% para AGCO (ANFAVEA, 2016). En Argentina hay una situación muy similar, con las tres empresas controlando las ventas de tractores en 2013 (con el mismo peso, $33 \%$ cada una). Las cosechadoras están controlados casi en su totalidad por John Deere (49\%) y CNH (45\%), dejando 6\% para AGCO (AFAT, 2014).

En el segmento de fertilizantes y fitosanitario también se produjo fusiones, adquisiciones y joint ventures, lo que provocó una reducción en el número de empresas y una fuerte concentración en este mercado. Aunque los datos no pueden ser tan precisos como en el caso de las máquinas, en Brasil la producción y distribución de fertilizantes pasa, principalmente, por Bunge, Fertipar, Cargill, Yara y Heringer (FERRI, 2010), mientras que en Argentina son Profertil, Nidera y ACA (Asociación de Cooperativas Argentinas), y las ya mencionadas Bunge, Cargill y Yara (ROMERO, 2015). En el sector fitosanitario en los dos países predominan las transnacionales Syngenta, Bayer, BASF, Monsanto, DuPont, Dow, Makhteshim, Nidera y FMC (SANTOS, 2012; ROMERO, 2015).

Un proceso similar se ha producido en el sector de la industrialización y exportación de soja, que está dominado por un pequeño número de grandes empresas. En Argentina, sólo ocho empresas controlaban el $80 \%$ de la capacidad instalada y la mayor parte de las exportaciones del segmento en 2010 (90\% del aceite, $85 \%$ del harina y $84 \%$ del grano). Las empresas nacionales - Aceitera General Deheza (AGD), Molinos Río de la Plata y Vicentín - tenían una capacidad 
de molienda de 22,7\% (hasta el inicio de la década de 2000 llegaba el 30\%) (HINRICHSEN, 2013). Entre las empresas transnacionales se destacan Cargill, Bunge, Dreyfus, ADM, Noble y Nidera. En los últimos 15 años, estas empresas se expandieron en el mercado argentino, controlando $58 \%$ de la capacidad de producción de aceites y respondiendo por $22 \%$ de las exportaciones totales de Argentina en 2011. En el segmento de soja representan $85 \%$ de las exportaciones in natura, 70\% del aceite y 54\% de la harina (MAGyP, 2016; PIERRI, 2014).

En Brasil son las empresas transnacionales Bunge, Cargill, ADM y Dreyfus, además de la brasileña Amaggi, que se convierten en las principales empresas del complejo soja en Brasil. Es importante señalar que hasta 1995 sólo Cargill tenía tres plantas de trituración de soja en Brasil. Después de un intenso proceso de fusiones y adquisiciones, ADM, Bunge, Dreyfus y Amaggi también comenzaron a tener el control sobre la propiedad de las unidades de procesamiento de grano, alcanzando el $50 \%$ de las condiciones nacionales de procesamiento de soja en 2009 , mientras que en 1995 representaban solo 6\% (WESZ JR., 2011). En Brasil hay una falta de datos de las exportaciones por empresa y producto, pero en términos generales se puede decir que en el año 2013, estas cinco empresas representaron el 8,9\% del total de las exportaciones en Brasil (MDIC, 2016).

En suma, hubo un proceso intenso y profundo de fusiones y adquisiciones en los últimos años, generando una fuerte concentración en los sectores de maquinaria agrícola, fertilizantes, fitosanitarios, agroindustrialización y exportación. En general, las empresas transnacionales líderes mundiales son las que actualmente conducen el complejo sojero en Brasil y Argentina. Las numerosas medidas aplicadas por el Estado, que fueron descriptas anteriormente permitieron esta concentración en compañías transnacionales. Al mismo tiempo, estas empresas fueron extremadamente importantes en la expansión de la soja en ambos países, ofreciendo un conjunto de productos y servicios esenciales para que se produzca el grano.

\section{CONSIDERAÇÕES FINAIS}

Gran cantidad de actores vinculados con la producción de granos (productores y entidades rurales, agroindustria y algunos investigadores vinculados al sector agrario) atribuyeron a las políticas de liberalización económica y al espíritu empresarial de los productores las razones principales del boom sojero en los países vecinos. En otra dirección, los resultados de este estudio muestran que fue determinante para la expansión de la soja en Brasil y Argentina la creciente demanda externa, el aumento internacional del precio y las políticas estatales que favorecieron su cultivo a fines del siglo XX.

Debe destacarse que las políticas de difusión estatal del cultivo no tuvieron resultados significativos en aumentos de producción mientras los Estados Unidos tuvieron el monopolio de las ventas mediante subsidios internos y a la exportación. Las oportunidades de ventas al exterior de soja fueron ocasionadas por profundos cambios en el comercio mundial, provocados por decisiones de política económica en países desarrollados (por ejemplo: abandono de subsidios al agro entre 1981 y 1985 en Estados Unidos, crisis de la agricultura soviética en 1972/73, decisiones del gobierno chino referidas a la importación de granos, mejoras en la alimentación en países en desarrollo, etc.) o iniciativas estrictamente políticas por parte del mayor exportador mundial, Estados Unidos, cuando estableció el boicot de exportación de granos a Irán y la URSS en 1980. Debe destacarse también que el crecimiento de exportaciones argentinas y brasileñas se concentró en un mercado mundial particular, el de soja y derivados, en el cual por la magnitud de su crecimiento 
(mucho mayor que de otros granos) y por el tipo de países demandantes, los Estados Unidos no pudieron mantener el grado de participación como si lo mantuvieron en el comercio mundial de otros granos.

Por otra parte, la acción estatal fue fundamental en inducir procesos de liberalización y privatización económica y comercial, flexibilización de las leyes de semilla (transgénicos), legislación sobre puertos industriales y/o profundización de vías navegables, creación de nuevos mercados (biodiesel), etc. dirigidas directamente a inducir la expansión del cultivo y el control de grandes empresas sobre la cadena agroindustrial. El contexto de globalización del sistema agroalimentario, generó las condiciones para el predominio de un pequeño grupo de empresas multinacionales en los sectores de maquinaria agrícola, fertilizantes, fitosanitarios, agroindustrialización y exportación. Actualmente, el complejo sojero en Brasil y Argentina es conducido por las mismas firmas líderes mundiales.

La influencia decisiva del factor externo, de las políticas públicas y de las grandes empresas transnacionales en las mismas décadas en Brasil y Argentina (que se repite en países vecinos como Paraguay y Uruguay) permite relativizar el grado de influencia del espíritu empresario de los productores y del funcionamiento estricto de mecanismos de libre mercado para explicar el "boom sojero". En gran medida el aumento de la producción ocurrió por medio de la expansión de la frontera y no por un espectacular crecimiento de la productividad por hectárea, siendo que en otros cultivos los aumentos de productividad/ha fueron superiores, pero la rentabilidad fue menor, situación derivada de la menor capacidad para incidir en el mercado mundial. La pregunta a formular es, ¿Porqué los aumentos de producción fueron mucho menores en otros granos o actividades agrarias en ambos países? La respuesta no parece derivar de estimar un distinto espíritu innovador schumpeteriano practicado en las distintas actividades sino de la determinante influencia de las oportunidades en el comercio mundial y las políticas estatales dirigidas a posibilitar el boom sojero en ambos países dependientes en mayor grado de la evolución del mercado mundial para explicar sus etapas de estancamiento o aumento de producción y exportaciones.

En el texto se quedo evidente las similitudes, complementariedades e interconexiones de la expansión de la soja en Brasil y Argentina. Pero, es importante reconocer que el grano también tiene fuerte influencia en Paraguay, Uruguay y Bolivia. Actualmente los cinco países constituyen la principal área de avance del cultivo de soja - en 2013 representaron más de la mitad de la producción mundial, mientras que en 1970 controlaban sólo el 4\% (FAOSTAT, 2014). Se resalta que Brasil y Argentina tienen gran influencia regional, no sólo al concentrar gran parte de la producción (90\%), sino también por "exportar" muchos actores a los otros países (productores rurales, empresas y cooperativas), tecnologías (OGM, siembra directa, agricultura de precisión, etc.) y modelos de producción, de gestión y de políticas públicas (GUIBERT et al., 2011; WESZ JR., 2014; GIRAUDO, 2014).

\section{REFERÊNCIAS}

ABIOVE - Associação Brasileira das Indústrias de Óleos Vegetais. Estatística. 2016. Disponível em: http://www.abiove.org.br/. Acesso em: 15 jan. 2016.

ANFAVEA - Associação Nacional dos Fabricantes de Veículos Automotores. Anuário da indústria automobilística brasileira de 2016. 2016. Disponível em: http://www.anfavea.com.br/. Acesso em: 25 jan. 2016. 
ANP - Agência Nacional do Petróleo, Gás Natural e Biocombustíveis. Anuário estatístico brasileiro do petróleo, gás natural e biocombustíveis - 2015. Rio de Janeiro: ANP, 2015.

BARROS, T. M. Análise e avaliação dos novos critérios de adjudicação de portos e terminais sob o novo marco regulatório do setor portuário brasileiro. 2014. 167f. Dissertação (Mestrado em Engenharia). Escola Politécnica da USP, São Paulo.

BCB - Banco Central do Brasil. Matriz de dados do crédito rural. 2016. Disponível em: http://www.bcb.gov.br/pt-br/sfn/credrural/. Acesso em: 28 jan. 2016.

CARNEIRO, R. Desenvolvimento em crise: a economia brasileira no último quarto do século XX. São Paulo: Editora Unesp/Unicamp, 2002.

CASTRO, A. C. Localização e identificação das empresas processadoras de soja, suas áreas de influência, preços e custos de transporte relacionados. Rio de Janeiro: CPDA/UFRRJ, 2002.

CONAB - Companhia Nacional de Abastecimento. Série histórica de produção. 2016. Disponível em: http://www.conab.gov.br. Acesso em: 23 jan. 2016.

DELGADO, G. C. Do capital financeiro na agricultura à economia do agronegócio: mudanças cíclicas em meio século. Porto Alegre: UFRGS, 2012.

.; CONCEIÇÃO, J. Políticas de preços agrícolas e estoques de alimentos: origens, situação atual e perspectivas. Revista Paranaense de Desenvolvimento n. 108, p. 25-32, 2005.

DU BOIS, C.; TAN, C. B.; MINTZ, S. (Eds.) The world of soy. Urbana: University of Illinois Press, 2009.

EMBRAPA - Empresa Brasileira de Pesquisa Agropecuária. Sistema de produção 6. 2004. Disponível em: http://www.cnpso.embrapa.br/. Acesso em: 28 jan. 2016.

FAOSTAT - División de Estadísticas de la FAO. Estadísticas generales. 2016. Disponível em: http://faostat.fao.org/. Acesso em: 23 jan. 2016.

FERNÁNDEZ, A. J. C. Do Cerrado à Amazônia: as estruturas sociais da economia da soja em Mato Grosso. 2007. 262f. Tese (Doutorado em Desenvolvimento Rural). Universidade Federal do Rio Grande do Sul.

FERNÁNDEZ, D. Incidencia de las políticas públicas en la estructura socioeconómica de la agricultura pampeana (2002-2008). Debates Urgentes, ano 2, n. 3, p. 157-191, 2013.

FERRI, F. A estrutura e a estratégia concorrencial da indústria de fertilizantes no Brasil. 2012. 72f. Monografia (Graduação em Economia). Universidade Federal do Rio Grande do Sul.

FLEXOR, G. G. A globalização do sistema agroalimentar e seus desafios para o Brasil. Economia Ensaios, v. 21, p. 63-96, 2006. 
JANVRY, A.; GARRAMON, C. Laws of motions of capital in the center periphery structure. Univ., Berkeley, 1976.

GILPIN, R. Global political economy: Understanding the international economic order. Princeton University Press, 2011.

GIRAUDO, M. E. The political economy of commodity regions: the case of soybean in South America. FLACSO-ISA, Buenos Aires, 2014.

GRAS, C.; HERNÁNDEZ, V. Los pilares del modelo agribusiness y sus estilos empresariales. In: GRAS, C.; HERNÁNDEZ, V. (ed.) El agro como negócio: producción, sociedad y territorios en la globalización. Buenos Aires: Biblios, 2013.

GUIBERT, M. et al. De Argentina a Uruguay: espacios y actores en una nueva lógica de producción agrícola. Pampa, n. 7, p. 13-88, 2011.

HINRICHSEN, J. J. Annual yearbook on oilseeds markets. Buenos Aires, 2013.

IBGE - Instituto Brasileiro de Economia e Estatística. Banco de dados agregados. 2016. Disponível em: http://www.sidra.ibge.gov.br. Acesso em: 28 jan. 2016.

INDEC - Instituto Nacional de Estadística y Censos. Agricultura. 2015. Disponível em: http://www.indec.gov.ar/agropecuario/. Acesso em: 28 jan. 2016.

KAGEYAMA, A. et al. O novo padrão agrícola brasileiro: do complexo rural aos complexos agroindustriais. In: DELGADO, G.C. (Org.). Agricultura e políticas públicas. Brasília/DF: IPEA, 1990.

LEITE, S. P. Inserção internacional e financiamento da agricultura brasileira (1980-1996). 1998. 258f. Tese (Doutorado em Economia). Universidade Estadual de Campinas.

.; WESZ Jr., V. J. Estado, políticas públicas e agronegócio no Brasil: revisitando o papel do crédito rural. Revista Pós Ciências Sociais, v. 11, n. 22, p. 83-108, 2014.

MAGyP - Ministerio de Agricultura, Ganadería y Pesca. Sistema integrado de información agropecuaria. 2016. Disponível em: http://www.siia.gov.ar/index.php. Acesso em: 27 fev. 2016.

MDIC - Ministério do Desenvolvimento, Indústria e Comércio Exterior. Indicadores e Estatísticas de Comércio Exterior. 2016. Disponível em: http://www.mdic.gov.br. Acesso em: 28 jan. 2016.

MONTES, G. C.; REIS, A. F. Investimento público em infraestrutura no período pósprivatizações. Economia e Sociedade, v. 20, n. 1 (41), p. 167-194, 2011.

MURPHY, S.; BURCH, D.; CLAPP, J. Cereal secrets: the world's largest grain traders and global agriculture. Oxfam Research Report. Oxford: Oxfam, 2012. 
OLIVEIRA, S V.; REYS, M. A. Estruturação e consolidação da produção do biodiesel - base de soja - no Rio Grande do Sul. Extensão Rural, Santa Maria, n. 17, p. 93116, 2009.

PENGUE, W. Producción agroexportadora e (in)seguridad alimentaria: el caso de la soja en Argentina. Revista Iberoamericana de Economía Ecológica, v. 1, p. 46-55, 2004.

PESSANHA, L.; WILKINSON, J. Transgênicos, recursos genéticos e segurança alimentar: que está em jogo nos debates? São Paulo: Armazém do Ipê, 2005.

PIERRI; J. Sector externo, política agraria y entidades del agro pampeano 1960/1986. Ediciones Cooperativas: Buenos Aires, 2007. $\overline{53-63,2006 .}$

El boom de la soja. Un retorno al pasado? Realidad Económica, n. 219, p. El sector externo y la producción de soja en Argentina 1960/2001. Documentos del CIEA. Buenos Aires, 2004. 2014.

Producción y comercio de granos 1980 - 2012. Buenos Aires: Biblios,

RAS, N. Academia Nacional de Agronomía y Veterinaria. Anales... TOMO XLVIII, Buenos Aires, 1994.

RATHMANN, R.; SILVEIRA, S. J. C.; SANTOS, O. I. B. Governança e configuração da cadeia produtiva do biodiesel no Rio Grande do Sul. Extensão Rural, Santa Maria, n. 15, p. 69-102, 2008.

REMUSSI, C.; PASQALE, A. La soja: su cultivo y utilización. Instituto Agronómico de Oleaginosas, Buenos Aires, UBA, 1973.

ROMERO, F. G. El imperialismo y el agro argentino: historia reciente del capital extranjero en el complejo agroindustrial pampeano. Buenos Aires: Ciccus, 2015.

SANTOS, R. G. Características, sistema de registros de produtos e concorrência no mercado de agrotóxicos no Brasil. Radar: tecnologia, produção e comércio exterior. Brasília: IPEA, 2012.

SCHIOSCHET, T.; PAULA, N. Soja transgênica no Brasil: os limites do processo de difusão tecnológica. Estudos Sociedade e Agricultura, v. 16, n. 1, p. 27-53, 2008.

SILVA MAZON, M. Padrões de qualidade e segurança alimentares no terreno institucional brasileiro. Revista Dados, v. 52, n. 4, p. 1003-1045, 2009.

TEUBAL, M. La crisis alimentaria y el tercer mundo: una perspectiva latinoamericana. Economía de América Latina, CIDE, México, 1979.

.; PALMISANO, T. ¿Hacia la reprimarización de la economía? Realidad Económica, n. 296, IADE, Buenos Aires, 2015. 
USDA - Departamento de Agricultura dos EUA. Data and statistics. 2014. Disponível em: http://www.usda.gov/wps/portal/usda/. Acesso em: 18 mar. 2016.

VIEIRA FILHO, J. E. R. Expansão da fronteira agrícola no Brasil: desafios e perspectivas. Texto para Discussão, IPEA, 2016.

WESZ Jr., V. J. O mercado da soja e as relações de troca entre produtores rurais e empresas no Sudeste de Mato Grosso (Brasil). 2014. 220f. Tese (Doutorado em Ciências Sociais). Universidade Federal Rural do Rio de Janeiro.

. Dinâmicas e estratégias das agroindústrias de soja no Brasil. Rio de Janeiro, E-papers, 2011.

WILKINSON, J; CASTELLI, P. G. A transnacionalização da indústria de sementes no Brasil: biotecnologias, patentes e biodiversidade. Rio de Janeiro: ActionAid, 2000.

.; WESZ Jr., V. J. Underlying issues in the emergence of China and Brazil as major global players in the new South-South trade and investment axis. International Journal of Technology Management \& Sustainable Development, v. 12, p. 245-260, 2013. 